\title{
Performance Evaluation of Two-Stage Electrokinetic Washing as Soil Remediation Method for Lead Removal using Different Wash Solutions
}

\section{Authors and Affiliation}

Y. S. Ng ${ }^{\text {a }}$ B. Sen Gupta ${ }^{b(+)}$, M. A. Hashim ${ }^{a *}$

${ }^{a}$ Department of Chemical Engineering, University of Malaya, 50603 Kuala Lumpur, Malaysia

${ }^{\mathrm{b}}$ School of Planning, Architecture and Civil Engineering, Queen's University Belfast, David Keir Building, Belfast BT9 5AG, UK

${ }^{(+)}$Current address: School of the Built Environment, Heriot-Watt University, Edinburgh Campus, EH14 4AS Scotland

\section{* Corresponding author}

Email : : alihashim@um.edu.my

Telephone number $\quad:+603-79675296$

Fax number $\quad:+603-79675319$

Postal Address : Department of Chemical Engineering, Faculty of Engineering, University of Malaya, 50603 Kuala Lumpur, Malaysia 


\section{ABSTRACT}

The study explores the application of a two-stage electrokinetic washing system on remediation of lead $(\mathrm{Pb})$ contaminated soil. The process involved an initial soil washing, followed by an electrokinetic process. The use of electrokinetic process in soil washing not only provided additional driving force for transporting the desorbed $\mathrm{Pb}$ away from the soil but also reduced the high usage of wash solution. In this study, the effect of $\mathrm{NaNO}_{3}, \mathrm{HNO}_{3}$, citric acid and EDTA as wash solutions on two-stage electrokinetic washing system were evaluated. The results revealed that a two-stage electrokinetic washing process enhanced $\mathrm{Pb}$ removal efficiency by $2.52-9.08 \%$ and $4.98-20.45 \%$ in comparison to a normal electrokinetic process and normal washing process, respectively. Low $\mathrm{pH}$ and adequate current were the most important criteria in the removal process as they provided superior desorption and transport properties. The effect of chelating by EDTA was less dominant as it delayed the removal process by forming a transport loop in anode region between $\mathrm{Pb}$ ion and complexes. $\mathrm{HNO}_{3}$ was not suitable as wash solution in electrokinetic washing in spite of offering highest removal efficiency as it caused $\mathrm{pH}$ fluctuation in the cathode chamber, corroded graphite anode and showed high power consumption. In contrast, citric acid not only yielded high $\mathrm{Pb}$ removal efficiency with low power consumption but also maintained a low soil: solution ratio of $1 \mathrm{~g}$ : $<1 \mathrm{~mL}$, stable $\mathrm{pH}$ and electrode integrity. Possible transport mechanisms for $\mathrm{Pb}$ under each wash solution are also discussed in this work.

Keywords: Two-stage electrokinetic washing, soil treatment, lead, wash solutions, transport mechanisms 


\section{Introduction}

Lead $(\mathrm{Pb})$ has been identified as one of the top six toxic threats in the world [1] as it can cause acute and chronic illnesses by damaging central and peripheral nervous systems, cardiovascular and reproductive systems as well as gastrointestinal and urinary tracts when it is inhaled and ingested [23]. As a result of its extensive use, humans are exposed to $\mathrm{Pb}$ via several pathways. One of the pathways is soil contamination. $\mathrm{Pb}$ concentration as high as $751.98-138,000 \mathrm{mg} / \mathrm{kg}$ was reported in shooting range soil, dumpsite for lead-acid battery as well as manufacturing and mining regions over the world [1, 4-6]. Therefore, a proper treatment must be conducted for these soils.

According to Dermont et al. [7], soil washing is one of the ex situ remediation methods for treating $\mathrm{Pb}$ and heavy metals contaminated soil especially for higher permeability soil that has lower silt and clay content [8]. There has been several studies on the treatment of $\mathrm{Pb}$ contaminated soil using different washing agents such as surfactants [9] acids [10] and chelating agents [11-13] and positive results have been reported. However, it is worth noting that one of the disadvantages of soil washing is the occurrence of spent chemicals in the wash solution and this increases the cost for treatment [7]. Moreover, a high ratio for soil: solution in the system of $1 \mathrm{~g}: 3.33-20 \mathrm{~mL}[9,11-12]$ is another disadvantage for soil washing as the amount of spent wash solution to be treated is large.

In contrast, electrokinetic soil remediation could reduce the amount of wash solution needed in remediating heavy metals contaminated soil. Electrokinetic process is a potential soil treatment method that uses electricity as the driving force for ion transport. The induction of low intensity direct current through the soil augments the transport of water and contaminants via two major mechanisms, namely electromigration for ion transport and electroosmosis for pore water/neutral compounds transport [14-16]. Electromigration transports the desorbed heavy metals in the wash solution/soil mixture towards the cathode chamber and they are concentrated in the chamber even in the absence of hydraulic flow. This further enhances desorption process as local concentration polarization in the soil/solution mixture can be minimised due to the removal of desorbed ions from the mixture via electromigration. As the wash solution only serves as a transport medium for the ions, the amount of wash solution used could be reduced as long as the soil is saturated by the wash solution. 
Y.S. Ng, B. Sen Gupta, M.A. Hashim, Performance Evaluation of Two-Stage Electrokinetic Washing as Soil Remediation Method for Lead Removal using Different Wash Solutions, Electrochimica Acta 147 (2014) 9-18. DOI: doi:10.1016/j.electacta.2014.08.124

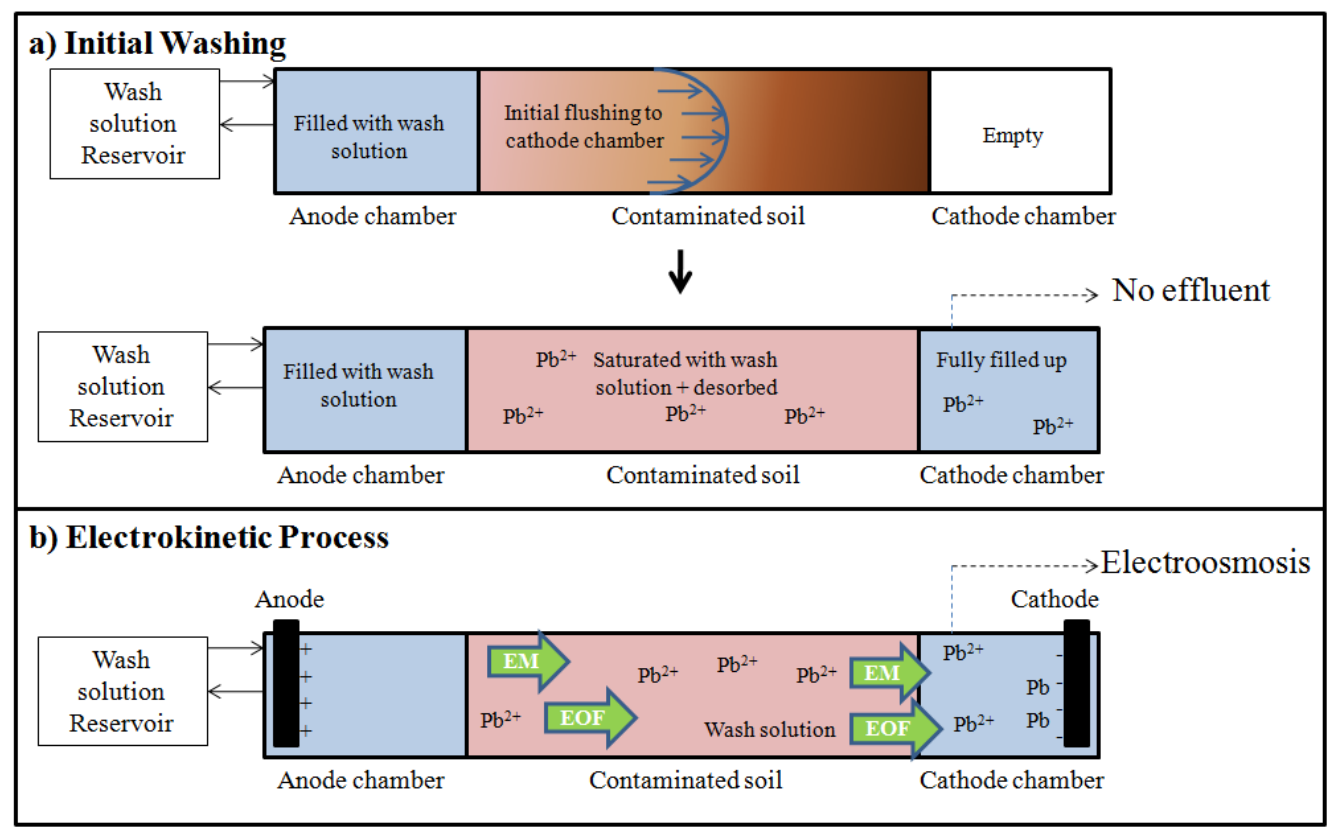

Fig. 1. Schematic diagram of two-stage electrokinetic washing process

In the present study, electrokinetic process is applied together with ex situ soil washing as a two-stage electrokinetic washing process to remove $\mathrm{Pb}$ from iron rich soil taken from Hulu Langat, Malaysia. The remediation process is carried out in two stages: i) initial soil washing, followed by ii) electrokinetic process, as shown in Fig. 1. Initial soil washing is initiated by filling up anode chamber with the wash solution while the cathode chamber is left empty. Due to the hydraulic gradient between the two chambers, the solution diffuses into the soil, wets the soil, desorbs and transports the $\mathrm{Pb}$ to the empty cathode chamber and fills it up. This stage stops when the cathode chamber is full. At this stage, electrokinetic process is introduced as the second stage of the treatment which serves as another driving force to further transport the remaining desorbed $\mathrm{Pb}$ towards the cathode chamber, as shown in Fig 1. Moreover, an in situ treatment of the wash solution in cathode chamber may also be conducted via $\mathrm{Pb}$ electro-deposition, which could further reduce the treatment cost for spent wash solution. Nevertheless, it is worth noting that two-stage electrokinetic washing process is only applicable for the soil that has higher permeability as initial soil washing process is normally poor for clayey soil [17].

The objective of this study was to evaluate the performance of a two-stage electrokinetic washing process as a soil treatment method for removing $\mathrm{Pb}$ from iron rich sandy soil. Efficiency comparisons between electrokinetic washing system and normal soil washing as well as normal electrokinetic processes were conducted. The performance of different types of wash solutions, namely $\mathrm{NaNO}_{3}$, acid based agents $\left(\mathrm{HNO}_{3}\right.$, Citric acid) and chelating agent EDTA in electrokinetic washing process were investigated not only from the aspect of removal efficiency but also their 
Y.S. Ng, B. Sen Gupta, M.A. Hashim, Performance Evaluation of Two-Stage Electrokinetic Washing as Soil Remediation Method for Lead Removal using Different Wash Solutions, Electrochimica Acta 147 (2014) 9-18. DOI: doi:10.1016/j.electacta.2014.08.124

impacts on the system, such as physical appearance of graphite electrodes and additional power consumption. Finally, possible transport mechanisms for each wash solution were also discussed.

\section{Experimental}

\subsection{Chemicals and soil contamination}

Table 1: Characteristic of the soil used in this study

\begin{tabular}{lll}
\hline Soil particle size distribution & \multicolumn{2}{c}{ Method } \\
\hline $50-850 \mu \mathrm{m}$ & $92 \%$ & \\
$2-50 \mu \mathrm{m}$ & $6 \%$ & Sieving \\
$<2 \mu \mathrm{m}$ & $2 \%$ & \\
\hline Soil properties & Value & Method \\
\hline $\mathrm{pH}$ & 3.97 & USEPA SW-846 Method 9045D \\
Specific Gravity & 2.5 & ASTM D 854 - Water pycnometer method \\
CEC (Meq) & 5.1 & Ammonium acetate method \\
Organic matter content & $1.4 \%$ & Loss of weight on ignition \\
\hline Soil metal content & Concentration & Method \\
& $(\mathbf{m g} / \mathbf{k g})$ & \\
\hline Iron $(\mathrm{mg} / \mathrm{kg})$ & 3719 & \\
Aluminium $(\mathrm{mg} / \mathrm{kg})$ & 2400 & \\
Manganese $(\mathrm{mg} / \mathrm{kg})$ & 185 & \\
Magnesium $(\mathrm{mg} / \mathrm{kg})$ & 635 & \\
Lead $(\mathrm{mg} / \mathrm{kg})$ & 11 & \\
Zinc $(\mathrm{mg} / \mathrm{kg})$ & 18 & \\
\hline
\end{tabular}

All the chemicals used in this study were of analytical grade and supplied by R\&M Chemicals (Malaysia). Soil was collected from Hulu Langat area, Malaysia and was sieved to $<0.85 \mathrm{~mm}$. The soil has high iron (Fe) content and is identified to have a potential risk for $\mathrm{Pb}$ contamination [18]. The adsorption capacity of this soil was determined experimentally as $1000 \mathrm{mg} / \mathrm{kg}$ from adsorption tests (data not shown), which is higher than the threshold concentration set up by Department of Environment Malaysia [19]. General properties of the uncontaminated soil were measured according to the procedures indicated in Table 1 . Artificial contaminated soil was used in this study by spiking the soil with $\mathrm{Pb}\left(\mathrm{NO}_{3}\right)_{2}$ solution to yield $1000 \mathrm{mg} / \mathrm{kg} \mathrm{Pb}$ contaminated soil by employing the reported method [20-21] without any $\mathrm{pH}$ adjustment. The mixture was mixed thoroughly using a spatula to homogenize the soil. Thereafter, the soil was dried for one week and was stored in a dark place prior to use. 
Y.S. Ng, B. Sen Gupta, M.A. Hashim, Performance Evaluation of Two-Stage Electrokinetic Washing as Soil Remediation Method for Lead Removal using Different Wash Solutions, Electrochimica Acta 147 (2014) 9-18. DOI: doi:10.1016/j.electacta.2014.08.124

\subsection{Experiment Procedures}

The experiments were carried out using a PTFE soil column with a dimension of $4 \mathrm{~cm}$ diameter and $15 \mathrm{~cm}$ length. A mass of $250 \mathrm{~g}$ of contaminated soil was compacted section by section in order to prevent air being trapped and this yielded an average soil voidage of 0.45 . The column packed with soil was then separated from the anode and cathode chambers using filter papers. The anode and cathode chambers, each having a size of $4 \mathrm{~cm}$ diameter and $7.4 \mathrm{~cm}$ length were connected to two ends of the column, with cylindrical graphite electrodes, as shown in Fig. 2. The overflow levels for both chambers were held at the same height so that the presence of electroosmotic flow (EOF) could be detected easily from the effluent flushed out from the cathode chamber. Four wash solutions were used in this study, namely $0.01 \mathrm{M} \mathrm{NaNO}$ (NANO3), $0.1 \mathrm{M} \mathrm{HNO}_{3}(\mathrm{HNO} 3), 0.1 \mathrm{M}$ citric acid (CIT) and $0.01 \mathrm{M}$ EDTA solution (EDTA) as they provided satisfactory $\mathrm{Pb}$ desorption in the preliminary shake flask study.

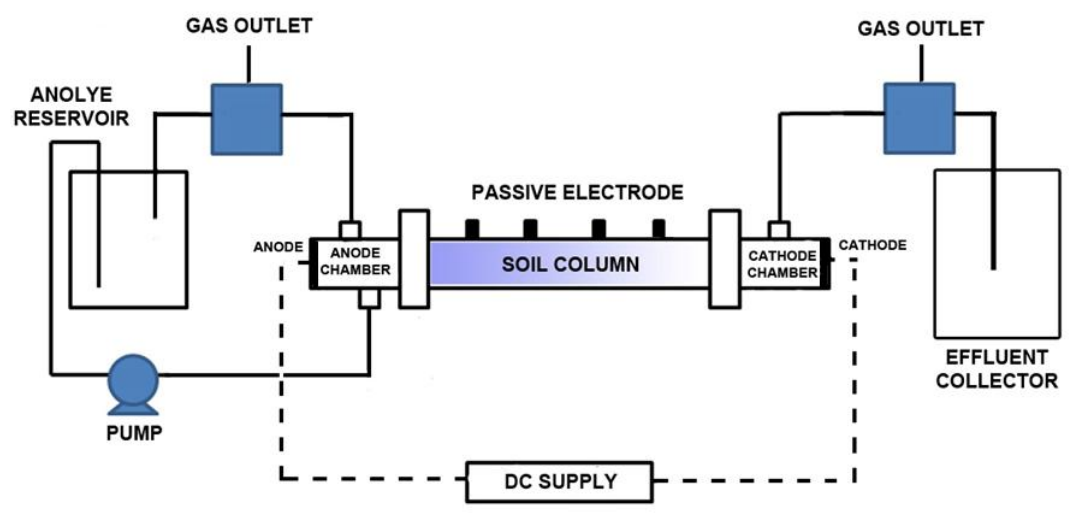

Fig. 2. Experimental setup for two-stage electrokinetic washing process

The experiment was conducted by pumping the wash solution into the anode chamber (anolyte) vertically from the bottom of the chamber at a rate of $15 \mathrm{~mL} / \mathrm{min}$ using a peristaltic pump while the cathode chamber was left empty. Soil washing process was initiated when the wash solution was transported through the soil column as a result of the hydraulic pressure gradient between the chambers, as illustrated in Fig. 1. Once the cathode chamber was filled up by the wash solution, electricity of $15 \mathrm{~V}$ was applied through the soil as the second driving force for 24 hours to further transport the desorbed $\mathrm{Pb}$ from the soil. The details of the experiments and the results are summarized in Table 2.

Experiments for normal soil washing and normal electrokinetic process were also conducted for comparison purpose. For normal soil washing, the experiments were conducted by repeating the procedures as mentioned above except the application of electricity. Instead, the soil/solution mixture was left 24 hours for $\mathrm{Pb}$ desorption process. For normal electrokinetic process, the soil was first 
Y.S. Ng, B. Sen Gupta, M.A. Hashim, Performance Evaluation of Two-Stage Electrokinetic Washing as Soil Remediation Method for Lead Removal using Different Wash Solutions, Electrochimica Acta 147 (2014) 9-18. DOI: doi:10.1016/j.electacta.2014.08.124

saturated with the wash solution and was subsequently compacted into the soil column. Following this, the soil column was separated from the chambers by filter papers and graphite electrodes were connected to the two ends of the chambers. In the next stage, both anode and cathode chambers were filled up with the wash solution and a constant voltage of $15 \mathrm{~V}$ was applied through the soil for 24 hours. No initial washing was involved in the tests for normal electrokinetic process.

Table 2: Experimental parameters and results for the present study

\begin{tabular}{|c|c|c|c|c|c|c|c|c|}
\hline \multirow[t]{2}{*}{ Test } & \multirow{2}{*}{$\begin{array}{c}\text { Voltage } \\
\text { applied, } \\
\text { V }\end{array}$} & \multirow{2}{*}{$\begin{array}{c}\text { Duration, } \\
\mathbf{h r}\end{array}$} & \multirow[b]{2}{*}{$\begin{array}{c}\text { Removal } \\
\text { Efficiency } \\
\text { by normal } \\
\text { soil } \\
\text { washing, \% }\end{array}$} & \multirow[b]{2}{*}{$\begin{array}{c}\text { Removal } \\
\text { Efficiency by } \\
\text { normal } \\
\text { electrokinetic } \\
\text { process, \% }\end{array}$} & \multicolumn{4}{|c|}{ Two-stage electrokinetic washing process } \\
\hline & & & & & $\begin{array}{c}\text { Removal } \\
\text { efficiency, } \\
\%\end{array}$ & $\begin{array}{c}\text { EOF, } \\
\text { mL }\end{array}$ & $\begin{array}{c}\text { Recovery } \\
\text { as } \\
\text { precipitate, } \\
\%\end{array}$ & $\begin{array}{c}\text { Power } \\
\text { consumption, } \\
\mathrm{kWh} / \mathrm{kg} \mathrm{Pb} \\
\text { removed }\end{array}$ \\
\hline NANO3 & 15 & 24 & 58.27 & 69.59 & 78.67 & 492.9 & 18.56 & 3.09 \\
\hline HNO3 & 15 & 24 & 95.01 & 97.47 & 99.99 & 288.5 & 64.65 & 114.47 \\
\hline CIT & 15 & 24 & 70.39 & 82.38 & 90.84 & 65.9 & 69.47 & 12.93 \\
\hline EDTA & 15 & 24 & 63.13 & 68.24 & 70.97 & 39.8 & 46.41 & 10.43 \\
\hline
\end{tabular}

\subsection{Analytical Method}

Electrical current across the soil was measured at the anode and cathode using Multimeter Sunwa TE-832B. The $\mathrm{pH}$ of the electrolytes was measured using Crison Multimeter MM26+ while soil $\mathrm{pH}$ was determined from USEPA SW-846 Method 9045D. Pb concentration was measured for: i) soil, and ii) precipitates. For soil concentration, the wash solution in soil column was removed after the experiments. The soil was then divided into five sections and $\mathrm{Pb}$ concentration in each section was determined using KSTM method [22]. The removal efficiency could be calculated from Equation (1), where $\mathrm{C}_{0}$ was the initial $\mathrm{Pb}$ concentration in soil and $\mathrm{C}_{\mathrm{t}}$ was average $\mathrm{Pb}$ concentration remained in the soil after the experiments. The amount of $\mathrm{Pb}$ precipitated on the cathode was determined by immersing the cathode into $150 \mathrm{~mL} 0.1 \mathrm{M} \mathrm{HNO}_{3}$ for 24 hours. $\mathrm{Pb}$ concentration in the aqueous sample was then analyzed using ICP-OES. The analysis was conducted triplicate and the results were within the error range of $\pm 4 \%$.

$$
\text { Re moval Efficiency, } \%=\frac{\mathrm{C}_{0}-\mathrm{C}_{\mathrm{t}}}{\mathrm{C}_{0}} \times 100
$$




\section{Results and Discussion}

\subsection{Efficiency comparison between two-stage electrokinetic washing and normal electrokinetic}

process as well as normal washing process

Table 2 shows that two-stage electrokinetic washing process achieved higher removal efficiency than the normal electrokinetic process. Removal efficiency was found to increase by $2.52 \%$ to $9.08 \%$. The higher removal efficiency for the two-stage electrokinetic washing process was mainly due to initial washing stage. In general, the initial washing induced a flushing effect for Pb desorption as well as migration to the cathode chamber in the highly permeable soil. This eventually provided initial $\mathrm{Pb}$ removal in comparison to the normal electrokinetic process and thus higher removal efficiency was achieved.

Two-stage electrokinetic washing process also showed higher removal efficiency than normal washing process whereby the removal efficiency was enhanced by $4.98 \%$ to $20.45 \%$. The enhancement was mainly due to the application of electricity along the soil which provided electromigration for $\mathrm{Pb}$ transport from the soil to cathode chamber. The removal of desorbed $\mathrm{Pb}$ from the soil prevented local concentration polarization while maintaining $\mathrm{Pb}$ desorption from soil:solution interface which further aiding the removal process. It is worth noting that significant electroosmotic flow (EOF) is detected in the electrokinetic process as the effluent is flushed out from the cathode chamber, as shown in Table 2. However, the effect of electroosmosis could be controlled by the current intensity and the nature of wash solution [23]. Electroosmosis was generally less significant than electromigration for ion transport. As shown in Table 2, the magnitude of EOF is not proportional to the efficiency enhancement in electrokinetic process as an EOF of $492.9 \mathrm{~mL}$ for NANO3 test and $65.9 \mathrm{~mL}$ for CIT test result in similar efficiency enhancements, i.e. $20 \%$. Instead, the efficiency enhancement under electrokinetic process is highly dependent on the type of wash solutions used. In this study, citric acid performed better as a wash solution in electrokinetic washing as the removal efficiency could be enhanced by $20.45 \%$ in comparison to the normal washing process. Furthermore, a high removal efficiency of $90.84 \%$ was achieved using this wash solution under electrokinetic washing process with a much lower soil: solution ratio at $1 \mathrm{~g}$ : $\langle 1 \mathrm{~mL}$ in comparison to other studies on soil washing which utilized a ratio of $1 \mathrm{~g}: 3.33-20 \mathrm{~mL}$ [9, 11-12]. 
Y.S. Ng, B. Sen Gupta, M.A. Hashim, Performance Evaluation of Two-Stage Electrokinetic Washing as Soil Remediation Method for Lead Removal using Different Wash Solutions, Electrochimica Acta 147 (2014) 9-18. DOI: doi:10.1016/j.electacta.2014.08.124

\subsection{Effect of wash solutions on Pb removal efficiency in two-stage electrokinetic washing process}

The removal efficiencies for two-stage electrokinetic washing process using different types of wash solutions follow a trend of HNO3 > CIT > NANO3 > EDTA, as shown in Table 2. This trend is in line with the order of soil $\mathrm{pH}$, as shown in Table 3 whereby the lower the soil $\mathrm{pH}$, the higher is the removal efficiency. In contrast to non-acidic agents, low $\mathrm{pH}$ condition created by acid-based agents was found to enhance $\mathrm{Pb}$ desorption from soil [24], resulting in higher removal via electromigration. On the other hand, a higher soil $\mathrm{pH} \cong 7$ in EDTA test was found to give the lowest removal efficiency as $\mathrm{Pb}$ mobility became lower due to possible precipitation. As the soil studied had low acid buffering capacity, it could be inferred that the soil $\mathrm{pH}$ and removal efficiency were significantly dependent on the $\mathrm{pH}$ of the wash solution used.

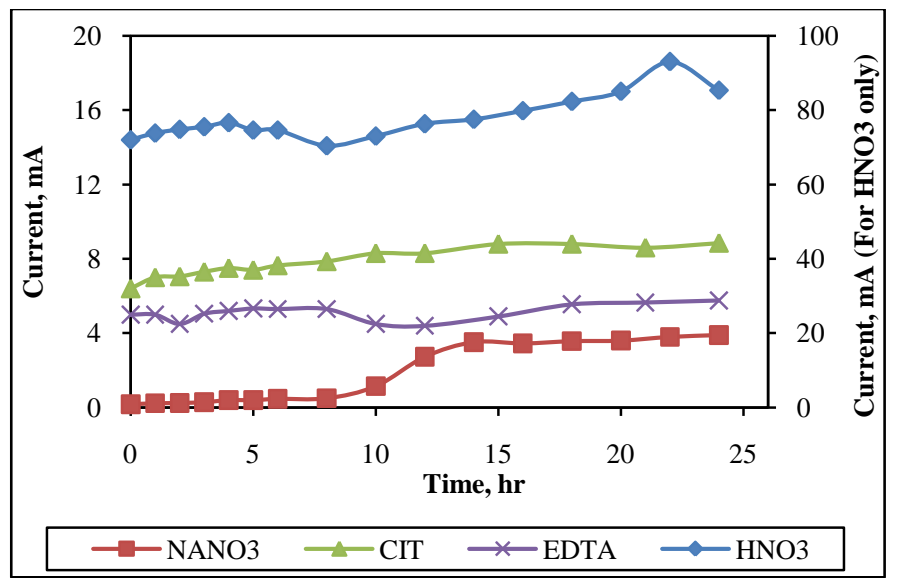

Fig. 3. Change of current in soil with time under different types of wash solutions

Other than soil $\mathrm{pH}$, the current across the soil from anode to cathode was another factor that affected metal ions transport as it determined electromigration rate. The current across the soil for different types of wash solutions are as shown in Fig. 3. The figure shows that the current is generally stable with no significant drop throughout the experiments. This is perhaps due to the relatively short experimental duration in comparison to previous studies [17, 25]. Nevertheless, it was worth noting that the magnitude of the current was governed by ionic strength and solvation power of the wash solutions, whereby it was in the order of NANO3 $<$ EDTA $<$ CIT $<$ HNO3. Acid-based agents which showed a current of $\approx 80 \mathrm{~mA}$ (HNO3) and $\approx 8 \mathrm{~mA}$ (CIT) was found to have higher current than EDTA $(\approx 5 \mathrm{~mA})$ and $\mathrm{NaNO}_{3}(\approx 4 \mathrm{~mA})$ as they were in higher concentration and they can enhance metal desorption and dissolution by providing low $\mathrm{pH}$ condition [26], which in turn increased ions concentration in aqueous phase. As the electromigration rate was directly dependent on the current, acid-based agents were found to provide higher removal efficiency. Among them, $\mathrm{HNO}_{3}$ yielded 10 
Y.S. Ng, B. Sen Gupta, M.A. Hashim, Performance Evaluation of Two-Stage Electrokinetic Washing as Soil Remediation Method for Lead Removal using Different Wash Solutions, Electrochimica Acta 147 (2014) 9-18. DOI: doi:10.1016/j.electacta.2014.08.124

times higher current than weaker citric acid, increasing the removal efficiency by $9.15 \%$ in comparison to citric acid.

In contrast, chelating agent EDTA was found to be less significant in enhancing the removal efficiency. Considering low organic matter in the soil (1.4\%), most of the $\mathrm{Pb}$ present in the soil was in exchangeable and $\mathrm{Fe}$ bounded conditions. Thus, the use of complexing/chelating agents for enhancing $\mathrm{Pb}$ solubility from the soil was less dominant than $\mathrm{Pb}$ dissolution under low $\mathrm{pH}$ condition. This was supported by EDTA test, which exhibited the lowest removal efficiency in electrokinetic washing process. Other than the soil $\mathrm{pH}$ mentioned above, this could also be attributed to the high iron content in the soil that may compete with $\mathrm{Pb}$ on complexation process and reduced the availability of EDTA for $\mathrm{Pb}$ [27]. In addition, the properties of anionic Pb-EDTA complexes that migrated towards the anode also caused low removal efficiency. As the complexation process was reversible [28], the excessive proton in the anode region as well as in the anode chamber resulting from electrolysis may cause the release of $\mathrm{Pb}$ ions back into the soil when anionic Pb-EDTA was transported to anode via electromigration. This argument was supported from the analysis for $\mathrm{Pb}$ residual in the soil at different soil sections. In general, lower $\mathrm{Pb}$ residual are observed in any soil section in electrokinetic washing (EW) tests in comparison to the tests that utilized normal washing (NW) as a result of electromigration, as shown in Table 3. This was true except for EDTA case whereby higher $\mathrm{Pb}$ residual was detected near the anode region (normalized distance from anode $<0.5$ ) in EDTA-EW test than in EDTA-NW test. Unlike in EDTA-NW test, which showed one way $\mathrm{Pb}$ transport, a higher $\mathrm{Pb}$ concentration near anode region in EDTA-EW test indicated the transport of Pb-EDTA complexes towards anode. Nevertheless, it is worth noting that a net transport of $\mathrm{Pb}$ to cathode chamber was still observed in EDTA-EW test as $\mathrm{Pb}$ concentration in anode chamber was found negligible while higher $\mathrm{Pb}$ content was detected in cathode chamber at the end of experiment. Detailed transport mechanisms are discussed in Section 3.5.

Table 3: Soil pH and normalized residual $\mathrm{Pb}$ concentration in soil at different soil sections (EW: electrokinetic washing; NW: normal washing)

\begin{tabular}{lcccccccccc}
\hline $\begin{array}{l}\text { Normalised } \\
\text { distance from } \\
\text { anode }\end{array}$ & \multicolumn{3}{c}{ Soil pH } & \multicolumn{4}{c}{$\begin{array}{c}\text { Normalised residual } \mathrm{Pb} \\
\text { concentration in soil, } \mathrm{C} / \mathrm{C}_{0}\end{array}$} \\
\cline { 2 - 12 } & 0.1 & 0.3 & 0.5 & 0.7 & 0.9 & 0.1 & 0.3 & 0.5 & 0.7 & 0.9 \\
\hline NANO3-EW & 4.21 & 3.97 & 4.1 & 4.2 & 4.41 & 0.03 & 0.11 & 0.20 & 0.35 & 0.38 \\
NANO3-NW & 5.2 & 4.55 & 4.38 & 4.2 & 4.2 & 0.33 & 0.35 & 0.39 & 0.47 & 0.55 \\
HNO3-EW & 2.54 & 2.6 & 2.64 & 2.66 & 2.69 & 0.00 & 0.00 & 0.00 & 0.00 & 0.00 \\
HNO3-NW & 2.51 & 2.54 & 2.59 & 2.58 & 2.59 & 0.00 & 0.02 & 0.04 & 0.07 & 0.12 \\
CIT-EW & 2.44 & 2.44 & 2.45 & 2.43 & 2.49 & 0.00 & 0.02 & 0.09 & 0.14 & 0.21 \\
CIT-NW & 2.57 & 2.5 & 2.51 & 2.52 & 2.5 & 0.08 & 0.20 & 0.30 & 0.45 & 0.45 \\
EDTA-EW & 8.03 & 7.78 & 7.19 & 6.5 & 7.53 & 0.04 & 0.14 & 0.33 & 0.42 & 0.52 \\
EDTA-NW & 8.38 & 7.86 & 6.68 & 5.02 & 4.33 & 0.04 & 0.05 & 0.21 & 0.59 & 0.95 \\
\hline
\end{tabular}


3.3 Effect of wash solutions on Pb precipitation on cathode in two-stage electrokinetic washing

process

In addition to the migration to the cathode chamber, $\mathrm{Pb}$ and metal ions were found to be discharged by the cathode and deposited on it under electrokinetic washing process. This phenomenon provided in situ treatment for spent wash solution in cathode chamber as it reduced the ions concentration. The deposition is highly dependent on the wash solutions, whereby acid-based agents provide higher precipitate recovery, as shown in Table 2 due to higher electrolysis rate. In addition, different physical observations were made under different wash solutions. Fig. 4a-i shows that white/brownish precipitates deposit on the cathode surface and some of the precipitates suspend in the effluent (Fig. 4a-ii) for NANO3 test. The precipitates were identified as lead hydroxide (white) and iron hydroxide (brown) as a result of high $\mathrm{pH}$ in the cathode chamber. In contrast, soft and malleable grey solids were collected on the cathode in HNO3, CIT and EDTA tests. The solids in HNO3 and EDTA tests were identified as $\mathrm{Pb}$ as the colour of the precipitates changed from grey to whitish yellow when they were dried in open air for one week, indicating $\mathrm{Pb}$ oxidation in the presence of moisture and oxygen. These are illustrated in Figs. 4b and 4d.

On the other hand, Fig. $4 \mathrm{c}$ shows a mixture of black and silver precipitates on the cathode surface when citric acid is used. The colour of the precipitates remained the same after drying at room temperature, suggesting that a mixture of metals were obtained. Unlike other tests which showed a soil texture similar to virgin soil after the experiment, smoother soil surface was obtained in CIT test. This is as shown in Fig. 5, which suggests extraction of $\mathrm{Pb}$ and other metals from the soil by citric acid. This inference is proven by SEM-EDX analysis on the precipitates, which show that they are primarily $\mathrm{Pb}$, with significant presence of other elements such as aluminium and titanium, as shown in Fig. 6. 
Y.S. Ng, B. Sen Gupta, M.A. Hashim, Performance Evaluation of Two-Stage Electrokinetic Washing as Soil Remediation Method for Lead Removal using Different Wash Solutions, Electrochimica Acta 147 (2014) 9-18. DOI: doi:10.1016/j.electacta.2014.08.124
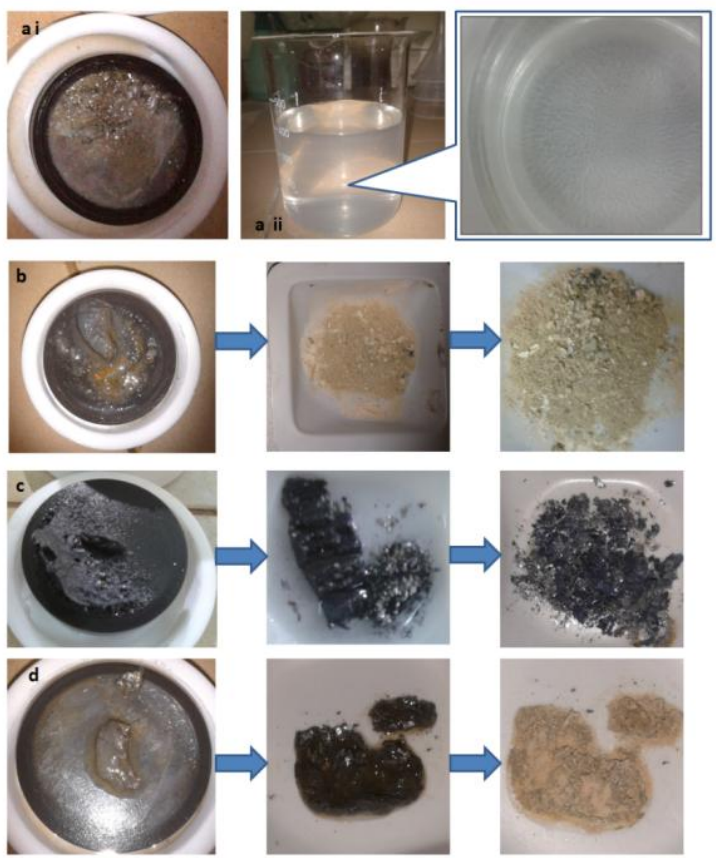

Fig. 4. Physical appearance of cathode and depositions a) NANO3, b) HNO3, c) CIT, d) EDTA
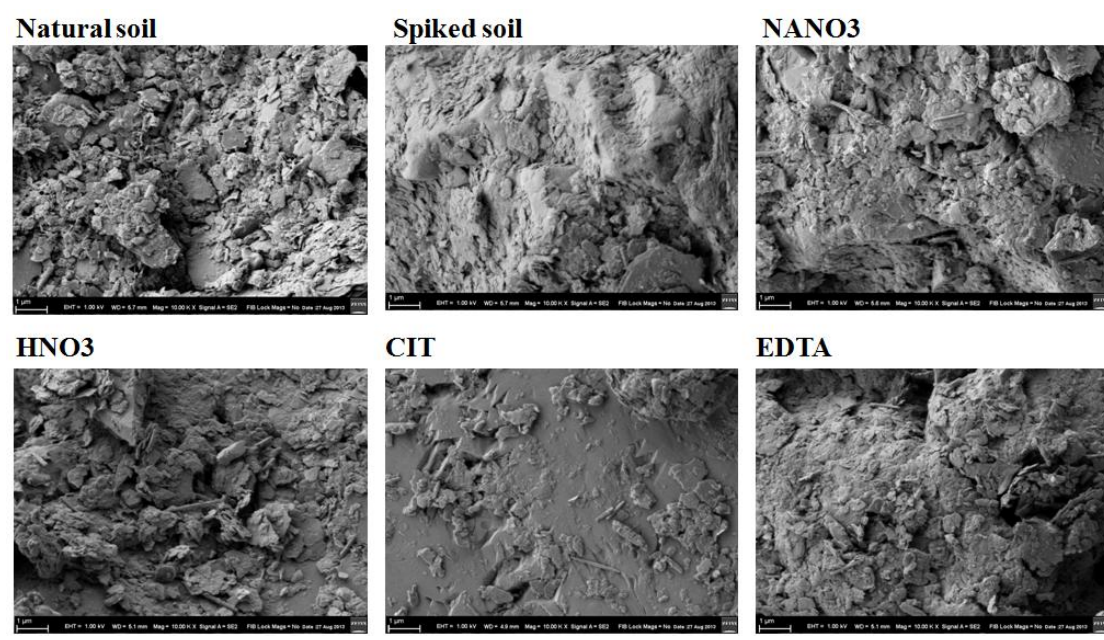

EDTA

Fig. 5. SEM imaging for the soil samples under different tests
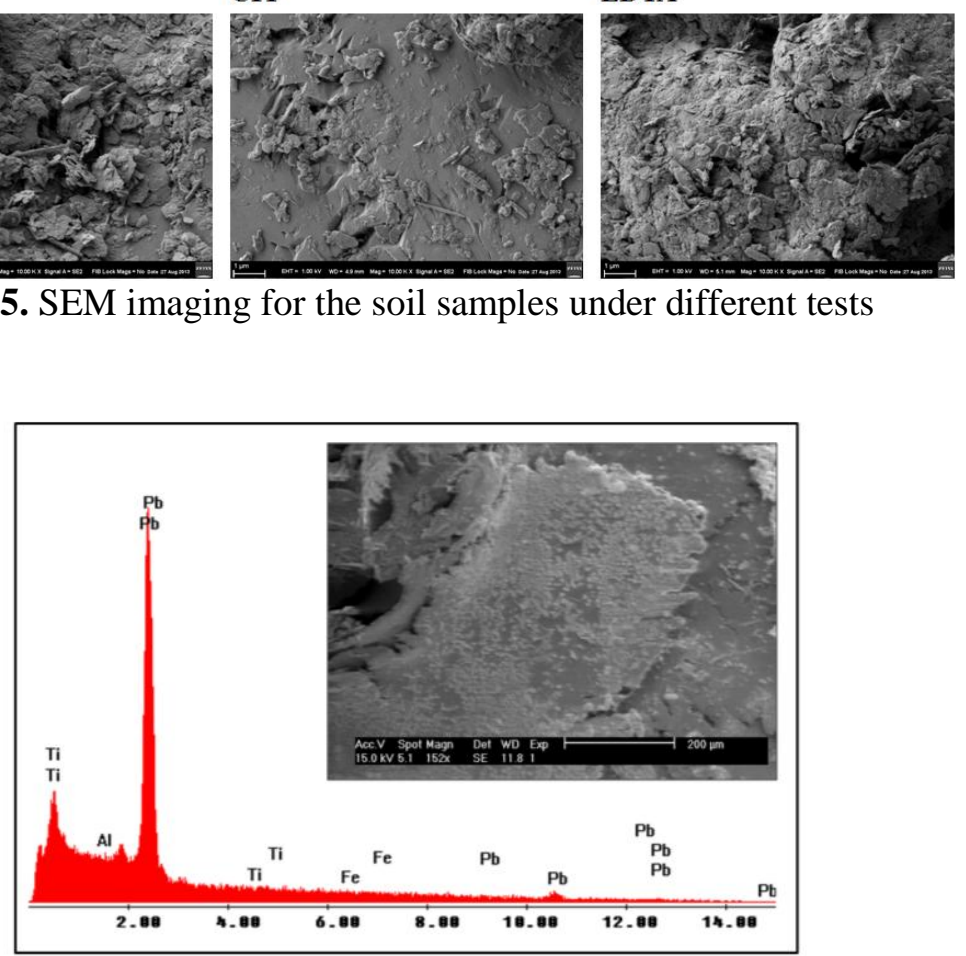

Fig. 6. SEM-EDX analysis for the precipitates obtained from CIT test 
Y.S. Ng, B. Sen Gupta, M.A. Hashim, Performance Evaluation of Two-Stage Electrokinetic Washing as Soil Remediation Method for Lead Removal using Different Wash Solutions, Electrochimica Acta 147 (2014) 9-18. DOI: doi:10.1016/j.electacta.2014.08.124

\subsection{Effect of wash solutions on the system in two-stage electrokinetic washing}

Other than the removal efficiency, the effect of wash solutions on the stability and additional power consumption of the electrokinetic washing system must be considered in order to justify the feasibility of the system. The parameters chosen in this study were i) effect to the electrolyte chambers, ii) effect to the electrodes, and iii) effect to power consumption for electrokinetic process.

\subsubsection{Effect to electrolyte chambers}
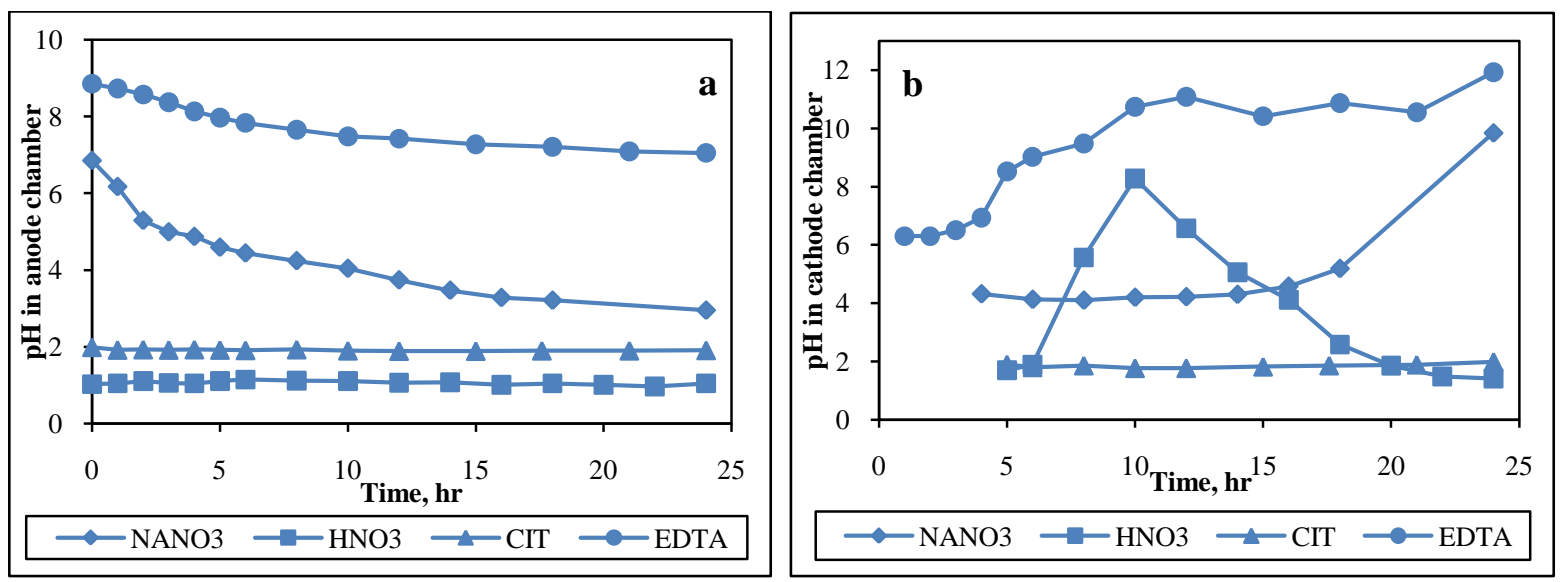

Fig. 7. Changes of $\mathrm{pH}$ in electrolyte chambers with time in two-stage electrokinetic washing: a) anode chamber; b) cathode chamber

Fig. 7 illustrates the change in $\mathrm{pH}$ for both anode and cathode chambers with time in electrokinetic washing. NANO3 and EDTA showed a decrease in anode chamber $\mathrm{pH}$ and an increase in cathode chamber $\mathrm{pH}$ as a result of electrolysis in the chamber, as explained by Equation (2) and (3), respectively $[14,29]$. In contrast, the application of acidic based agents $\mathrm{HNO}_{3}$ and citric acid provided a low and stable $\mathrm{pH}(1-2)$ in the anode chamber. However, different observations were obtained for the cathode chamber.

$$
\begin{aligned}
& 2 \mathrm{H}_{2} \mathrm{O} \rightarrow \mathrm{O}_{2}+4 \mathrm{H}^{+}+4 e^{-} \\
& 2 \mathrm{H}_{2} \mathrm{O}+2 e^{-} \rightarrow \mathrm{H}_{2}+2 \mathrm{OH}^{-}
\end{aligned}
$$

Citric acid in CIT test served as a buffer solution to nullify the $\mathrm{OH}^{-}$generated in cathode chamber. It also stabilised $\mathrm{pH}$ in the cathode chamber close to its initial $\mathrm{pH} \cong 2$. In contrast, $\mathrm{HNO} 3$ test which utilises $\mathrm{HNO}_{3}$ shows a $\mathrm{pH}<2$ until the $6^{\text {th }}$ hour, as shown in Fig. 7b. Thereafter, a rapid increase in $\mathrm{pH}$ is observed and a maximum $\mathrm{pH}$ of 8.28 is achieved at the $10^{\text {th }}$ hour. This unusual trend 
was also noticed by Almeira $\mathrm{O}$ et al. [30] when acid concentration was higher than $0.12 \mathrm{M}$. It is suggested that under high $\mathrm{HNO}_{3}$ concentration, $\mathrm{NO}_{3}{ }^{-}$ions are reduced and more $\mathrm{OH}^{-}$are produced, as shown in Equations (4)-(7) [30]. Excessive $\mathrm{OH}^{-}$prevailed over the $\mathrm{H}^{+}$ions in the cathode chamber, which increased the chamber's $\mathrm{pH}$. However, the $\mathrm{pH}$ was found to decrease again after the $10^{\text {th }}$ hour and eventually reduced to 1.41. After the consumption of $\mathrm{NO}_{3}{ }^{-}$in the cathode chamber during the first 10 hours of experiment, overall $\mathrm{pH}$ in the cathode chamber was again reduced to acidic condition by the acid front.

$$
\begin{aligned}
& \mathrm{NO}_{3}^{-}+2 e^{-}+\mathrm{H}_{2} \mathrm{O} \rightarrow \mathrm{NO}_{2}^{-}+2 \mathrm{OH}^{-} \\
& 2 \mathrm{NO}_{3}^{-}+16 e^{-}+12 \mathrm{H}_{2} \mathrm{O} \rightarrow 2 \mathrm{NH}_{3}+18 \mathrm{OH}^{-} \\
& 2 \mathrm{NO}_{3}^{-}+10 e^{-}+6 \mathrm{H}_{2} \mathrm{O} \rightarrow \mathrm{N}_{2}+2 \mathrm{OH}^{-} \\
& \mathrm{NO}_{3}^{-}+7 \mathrm{H}^{+} \rightarrow \mathrm{NH}_{4}+3 \mathrm{OH}^{-}
\end{aligned}
$$

\subsubsection{Effect to electrodes}

Other than the $\mathrm{pH}$ fluctuation, $\mathrm{HNO}_{3}$ was also found to corrode graphite electrodes. Unlike other wash solutions, which showed stable graphite anodes after the experiment, anode corrosion was observed in HNO3 test. In comparison to original electrode (Fig. 8a), formation of a layer of corroded graphite and accumulation of carbon particles in the anode chamber are observed in this test, as shown in Fig. 8b. The carbonaceous particles were graphite oxides, which were reported to be produced by $\mathrm{HNO}_{3}$ under strong oxidizing condition [31]. This condition was observed in $\mathrm{HNO} 3$ test as the anode was in strong oxidizing condition due to electrolysis process. Thus, it can be suggested that $\mathrm{HNO}_{3}$ is unsuitable as a wash solution in electrokinetic washing process when graphite is used as an electrode even though it shows highest removal efficiency among the wash solutions as it not only causes corrosion, but also contaminates the wash solution with graphite oxides particles.

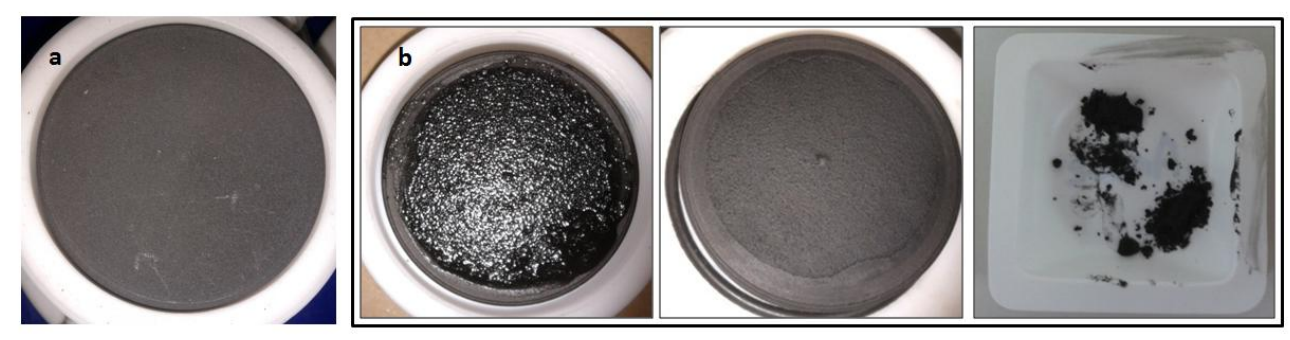

Fig. 8. Physical appearance of anode and graphite oxides after the experiment for $\mathrm{HNO} 3$ test 


\subsubsection{Effect to power consumption for electrokinetic process}

The application of two-stage electrokinetic washing process results in additional electric power consumption for the electrokinetic process (electromigration transport of $\mathrm{Pb}$ ) and this contributes additional operating cost in comparison to normal soil washing. Additional power consumed by the electrokinetic process was calculated using Equation (8), where $\mathrm{E}$ is the power consumed per $\mathrm{kg} \mathrm{Pb}$ removed $(\mathrm{kWh} / \mathrm{kg}), \mathrm{m}_{\mathrm{Pb}}$ is the mass of $\mathrm{Pb}$ removed $(\mathrm{kg}), \mathrm{V}$ is the voltage used $(\mathrm{V}), \mathrm{I}$ is the current across the soil (A), and $\mathrm{t}$ is the time (h).

$$
E=\frac{1}{m_{P b}} \int_{0}^{t} V I . d t
$$

Table 2 shows that acid-based agents consume more electrical power in electrokinetic washing process but yield higher removal efficiency than the other two. For acid-based agents which showed higher removal efficiency, $\mathrm{HNO}_{3}$ consumed nearly 10 times more power than citric acid $(114.47 \mathrm{kWh} / \mathrm{kg} \mathrm{Pb}$ vs $12.93 \mathrm{kWh} / \mathrm{kg} \mathrm{Pb})$. However, this only enhanced removal efficiency by about 9.15\% compared to citric acid. Moreover, $\mathrm{HNO}_{3}$ which consumed the highest power also showed lower $\mathrm{Pb}$ recovery on electrode in comparison to citric acid. Thus, it can be suggested that citric acid is a better choice as a wash solution in the electrokinetic washing process for treating this soil as it not only results in high removal and precipitate recovery but also provides stable condition to cathode chamber and graphite anode while consuming lower power in electrokinetic stage.

\subsection{Transport mechanisms of $\mathrm{Pb}$ in two-stage electrokinetic washing process}

Based on the experimental results, transport mechanisms of $\mathrm{Pb}$ in a two-stage electrokinetic washing process under different types of wash solutions can be suggested. In general, the transport mechanisms can be divided into two sections: i) $\mathrm{Pb}$ desorption via initial washing process, and ii) $\mathrm{Pb}$ transport via electrokinetic process. Fig. 9a shows that $\mathrm{Pb}$ desorption occurs when the wash solution contacts with the soil surface via diffusion or complexation. Some of the desorbed $\mathrm{Pb}$ ions are transported to the cathode chamber via wash solution. Then, the electric current further transports the suspended ions in the soil column towards their respective chamber, as shown in Fig. 9b. In this study, the use of different types of wash solutions show different mechanisms due to their abilities to provide desorption condition and also current for electromigration. 


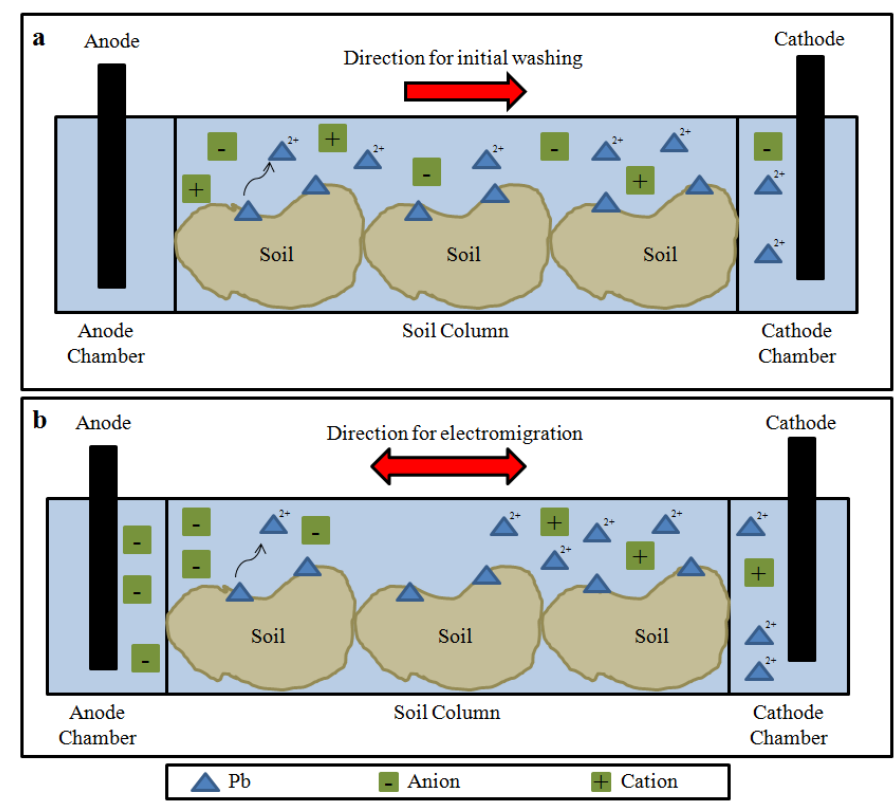

Fig. 9. General transport mechanisms in a two-stage electrokinetic washing process: a) initial washing; b) electrokinetic process

Fig. 10 illustrates a) $\mathrm{Pb}$ desorption from a soil particle via soil washing, and b) $\mathrm{Pb}$ transport in electrokinetic process under different types of wash solutions. The components that are not involved in the transport mechanisms are not shown in the figures. In general, when $\mathrm{NaNO}_{3}$ and $\mathrm{HNO}_{3}$ are used, the desorption process is mainly dependent on the partition coefficient of $\mathrm{Pb}$ between soil and wash solution, which is a function of $\mathrm{pH}$ [32]. Low $\mathrm{pH}$ condition could give higher $\mathrm{Pb}$ desorption, especially when complexation process is insignificant, as $\mathrm{NO}_{3}{ }^{-}$is not capable to complex with $\mathrm{Pb}$ [27]. On the other hand, citric acid not only provides low $\mathrm{pH}$ condition for $\mathrm{Pb}$ desorption but also detachment of surface ions via its viscosity and complexation with citrate anions [33]. As shown in Fig. $10 \mathrm{a}, \mathrm{Pb}$ is desorbed from soil surface into the aqueous phase due to low $\mathrm{pH}$ condition. Then, the

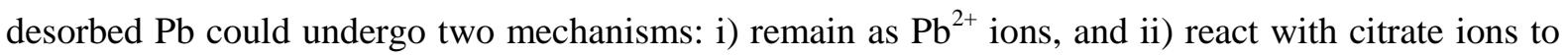
form water soluble complexes. The possible complexes formed are suggested to be $\mathrm{PbCitrate}^{+}$, as the $\mathrm{pH}$ of the soil system is in the range of 2.4-2.6, as shown in Table 3. Under this $\mathrm{pH}$, the citrate ions in the system will be mostly in undissociated form with minor citrate', as the acid dissociation constant, pKa for citric acids are 3.13, 4.76, and 6.40, respectively [34]. The dissociations of citric acid at different $\mathrm{pKa}$ are as shown in Equations (9)-(11). For EDTA, a higher soil pH range of 4.33-8.38 is observed and $\mathrm{Pb}$ is preferentially adsorbed or precipitated on the soil surface [35-36]. In this case, the main desorption mechanism for $\mathrm{Pb}$ from soil is by combining with EDTA to form water soluble complexes. EDTA has four dissociation stages with pKa of 1.99, 2.67, 6.14, and 10.26 [37] At soil pH of 4.33-8.38, the EDTA anions have charges of $-2,-3$, and -4 and thus the complexes formed are mostly negatively charged, as shown in Fig. 10a. 


$$
\begin{array}{ll}
\boldsymbol{H}_{3} \text { Cit } \Leftrightarrow \boldsymbol{H}_{2} \boldsymbol{C i t}^{-}+\boldsymbol{H}^{+} & \mathrm{pKa}_{1}: 3.13 \\
\boldsymbol{H}_{2} \boldsymbol{C i t}^{-} \Leftrightarrow \boldsymbol{H C i t}^{2-}+\boldsymbol{H}^{+} & \mathrm{pKa}_{2}: 4.76 \\
\boldsymbol{H C}_{\boldsymbol{C}}{ }^{2-} \Leftrightarrow \boldsymbol{C i t}^{3-}+\boldsymbol{H}^{+} & \mathrm{pKa}_{3}: 6.40
\end{array}
$$

After the soil is saturated with the wash solution, the use of electricity could provide electromigration as an additional driving force to transport the desorbed $\mathrm{Pb}$, whereby the cations will move to cathode chamber and anions will move to anode chamber. Fig. 10b shows that in NANO3 test, the use of electricity provides electromigration for removing desorbed $\mathrm{Pb}$ from the soil towards the cathode chamber and reduces local concentration polarization. Thus, higher desorption and removal is achieved in comparison to normal washing process. One way $\mathrm{Pb}$ transport is also observed for the cases of $\mathrm{HNO} 3$ and $\mathrm{CIT}$ as $\mathrm{Pb}$ ions/complexes are in cationic forms and are transported towards cathode chamber via electromigration. However, different mechanism is observed for EDTA test. Unlike the CIT case, the complexes formed are anions. Several mechanisms occur when electricity is induced, as shown in Figure 10b:

i) $\mathrm{Pb}$-EDTA anionic complexes are moving towards anode chamber via electromigration,

ii) EDTA is taken by the anode under high oxidizing condition and $\mathrm{Pb}^{2+}$ is released due to the complexation formed is a reversible process [28],

iii) $\mathrm{Pb}^{2+}$ is again transported into the soil section and heads towards cathode region due to its cationic behavior,

iv) during electromigration in soil column, $\mathrm{Pb}^{2+}$ encounters EDTA anion that is transported towards the anode chamber and forms Pb-EDTA anionic complexes again,

v) $\mathrm{Pb}^{2+}$ released may also adsorb onto the soil surface during the process as a result of high soil $\mathrm{pH}$.

The mechanisms stated in step (v) and the transport loop formed from steps (i) to (iv) are suggested as the main reasons why higher $\mathrm{Pb}$ residual is observed near anode region in electrokinetic washing than normal flushing when EDTA is used, as shown in Table 3. It is worth noting that this loop will continue until exhaustion of EDTA anions in the soil system. Upon this, $\mathrm{Pb}$ cation transport, as shown in step (vi) takes place. These mechanisms consequently delay the removal process and results in the lowest removal efficiency among the electrokinetic washing tests. 
Y.S. Ng, B. Sen Gupta, M.A. Hashim, Performance Evaluation of Two-Stage Electrokinetic Washing as Soil Remediation Method for Lead Removal using Different Wash Solutions, Electrochimica Acta 147 (2014) 9-18. DOI: doi:10.1016/j.electacta.2014.08.124
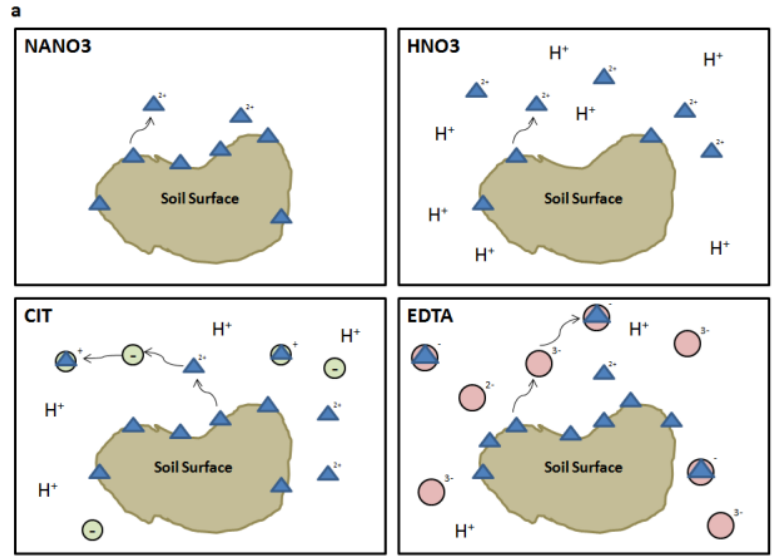

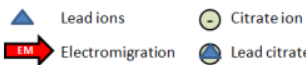
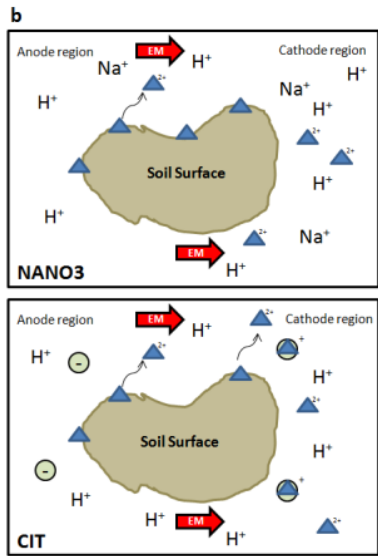

EDTAanion
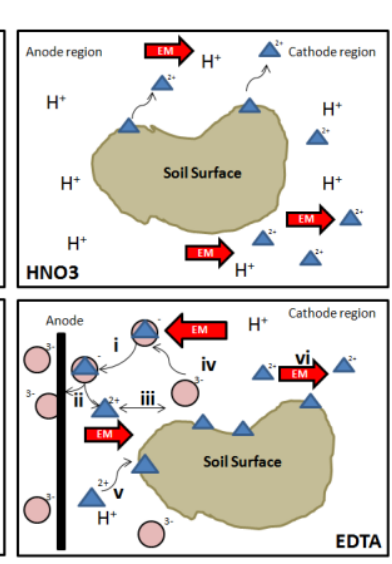

EDTA

Fig. 10. Schematic diagram for a) $\mathrm{Pb}$ desorption and b) $\mathrm{Pb}$ transport in electrokinetic process under different types of wash solutions.

\subsection{Comparison with other electrokinetic studies}

Table 4

Comparison between the present study with other studies on $\mathrm{Pb}$ removal from sandy soil using electrokinetic process

\begin{tabular}{|c|c|c|c|c|c|c|c|}
\hline References & Soil Type & $\begin{array}{c}\text { Organic } \\
\text { matter } \\
\text { content, \% }\end{array}$ & $\begin{array}{c}\text { Type of } \\
\text { contamination }\end{array}$ & $\begin{array}{c}\text { Initial Pb } \\
\text { concentration, } \\
\text { mg/kg }\end{array}$ & $\begin{array}{l}\text { Best wash } \\
\text { solutions }\end{array}$ & $\begin{array}{c}\text { Duration, } \\
\text { day }\end{array}$ & $\begin{array}{c}\text { Highest } \\
\text { Removal } \\
\text { efficiency, } \\
\%\end{array}$ \\
\hline [25] & Sand & $1.2 \%$ & Real & 4432 & $\begin{array}{c}\text { EDTA - } \\
\mathrm{NaOH}\end{array}$ & 10 & $36.28 \%$ \\
\hline [20] & Sand & $1.2 \%$ & Real & 5000 & $\begin{array}{c}\text { EDTA- } \\
\text { Tween } 80\end{array}$ & 30 & $82.4 \%$ \\
\hline [27] & $\begin{array}{c}80.2 \% \\
\text { sand }\end{array}$ & $13.3 \%$ & Real & 85 & $\begin{array}{l}\mathrm{HCl} \text {, citric } \\
\text { acid }\end{array}$ & 15 & $58 \%-68 \%$ \\
\hline [17] & $\begin{array}{c}44.36 \% \\
\text { sand }\end{array}$ & $4.15 \%$ & Real & $11.49-504.61$ & $\begin{array}{c}\text { EDTA - } \\
\mathrm{NaOH}\end{array}$ & $28-98$ & $19.4-23.9 \%$ \\
\hline [23] & $\begin{array}{l}89-98.5 \% \\
\text { sand }\end{array}$ & - & $\begin{array}{l}\text { Spiked with } \\
\mathrm{PbCO}_{3}\end{array}$ & 500 & Acetic acid & 1 & $>75 \%$ \\
\hline $\begin{array}{l}\text { Present } \\
\text { study }\end{array}$ & $92 \%$ sand & $1.4 \%$ & $\begin{array}{l}\text { Spiked with } \\
\mathrm{Pb}\left(\mathrm{NO}_{3}\right)_{2}\end{array}$ & 1000 & Citric acid & 1 & $90.84 \%$ \\
\hline
\end{tabular}

Table 4 provides a summary of different studies on electrokinetic remediation for $\mathrm{Pb}$ removal from sandy soil. In general, the electrokinetic process is proven as one of the effective treatment options for high permeability soil. However, high variation in removal efficiency is observed, as shown in Table 4. This variation could be due to the difference in system's characteristics such as soil structure, organic matter content, electrokinetic configurations and the operating scale/conditions, making direct comparison difficult. Nevertheless, as indicated in Table 4, the real and aged contaminated soil often shows lower removal efficiency and requires higher treatment duration in comparison to spiked soil and this could be due to their stronger binding on the soil surface. 
Y.S. Ng, B. Sen Gupta, M.A. Hashim, Performance Evaluation of Two-Stage Electrokinetic Washing as Soil Remediation Method for Lead Removal using Different Wash Solutions, Electrochimica Acta 147 (2014) 9-18. DOI: doi:10.1016/j.electacta.2014.08.124

Moreover, the $\mathrm{Pb}$ species in the soil is another parameter that causes different results and mechanisms. For example, the work of Murillo-Rivera et al. [23] shows the best removal was achieved by acetic acid while citric acid shows poor removal due to accumulation of $\mathrm{Pb}$ in the middle of the soil section. Low $\mathrm{Pb}$ removal was reportedly caused by low mobility of $\mathrm{Pb}$-citrate in the soil and low carbonate dissolution due to Pb-citrate sorption on the soil surface [23]. However, this observation was not found in the present study. This could be due to the difference in $\mathrm{Pb}$ source as spiking materials. In the present study, $\mathrm{Pb}$ was mainly adsorbed on the soil surface as Fe bounded species while $\mathrm{Pb}$ was presented as water insoluble carbonate salt as the contaminants as claimed in another report [23]. This shows that $\mathrm{Pb}$ species in the contaminated soil has significant influence on the performance of a wash solution. From this observation, it is suggested that the proposed transport mechanisms and the observed performance of the wash solutions would apply mainly to soil contaminated with $\mathrm{Pb}$, bounded to the $\mathrm{Fe}$ in soil. In order to further evaluate the feasibility of twostage electrokinetic washing process, future studies are required for other types of soil and metal species.

\section{Conclusions}

This study investigated the feasibility of a two-stage electrokinetic washing system on remediation of $\mathrm{Pb}$ contaminated soil from Hulu Langat, Malaysia. The system showed higher $\mathrm{Pb}$ removal efficiency than normal electrokinetic process as the initial washing provided flushing effect which contributed to $\mathrm{Pb}$ removal from soil before electrokinetic process was applied. Moreover, this process was also found to give better removal efficiency than normal soil washing as the supply of electric current supported electromigration as an additional driving force to transport desorbed $\mathrm{Pb}$ away from the soil and reduced local concentration polarization. Effluent was generated as a result of electroosmosis although hydraulic gradient was minimised in this work. However, it may be mentioned that electroosmosis was found to be less significant than electromigration on $\mathrm{Pb}$ removal and the amount of effluent generated could be controlled by the types of wash solution used.

The $\mathrm{pH}$ and electric current were the main factors that governed the removal process in electrokinetic washing while complexation between $\mathrm{Pb}$ and EDTA was less dominant. The acid based agents showed high $\mathrm{Pb}$ removal efficiency in comparison to EDTA and $\mathrm{NaNO}_{3}$ as they provided lower $\mathrm{pH}$ conditions and higher current across the soil. EDTA was unsuitable as it delayed the removal process by forming a transport loop in the anode region between $\mathrm{Pb}$ cation and $\mathrm{Pb}$-EDTA anionic complexes. $\mathrm{HNO}_{3}$ was found to be unsuitable as a wash solution as it caused $\mathrm{pH}$ fluctuation in cathode chamber, corroded graphite anode and showed high power consumption. In contrast, citric acid showed high removal efficiency of $90.84 \%$ at an effective soil: solution ratio of $1 \mathrm{~g}$ : < $1 \mathrm{~mL}$ with 
low power consumption while maintaining stable $\mathrm{pH}$ for the system and integrity of the graphite electrodes.

\section{Acknowledgment}

This work is a part of a collaborative project between Queen's University Belfast and University of Malaya and is financially supported by grant UM-QUB6A-2011 and PPP grant PG143-2012B, University of Malaya.

\section{References}

[1] A. McCartor, D. Becker, Blacksmith Institute's World Worst Pollution Probelm Report 2010, Blacksmith Institute, New York, 2010.

[2] J.O. Duruibe, M.O.C. Ogwuegbu, J.N. Egwurugwu, Heavy metal pollution and human biotoxic effects, Int. J. Phys. Sci. 2 (2007) 112-118.

[3] R.A. Wuana, F.E. Okieimen, Heavy metals in contaminated soils: A review of sources, chemistry, risks and best available strategies for remediation, International Scholarly Research Network Ecology, 2011 (2011) 1-20.

[4] S.A. Adejumo, A.O. Togun, J.A. Adediran, M.B. Ogundiran, Effects of compost application on remediation and the growth of maize planted on lead contaminated soil, in: 19th World Congress of Soil Science Symposium 3.5.1: Heavy Metal Contaminated Soils, Brisbane, Australia, 1-6 August 2010.

[5] Y. Hashimoto, K. Tajima, H. Yamada, T. Sato, Rhizosphere bacterial community PCR-DGGE profiles and metal speciation in shooting range soils, in: 19th World Congress of Soil Science Symposium 3.5.1: Heavy Metal Contaminated Soils, Brisbane, Australia, 1-6 August 2010.

[6] R.-Y. Kim, J.-K. Sung, S.-C. Kim, B.-C. Jang, Y.-S. Ok, Effect of calcined eggshell on fractional distribution and plant uptake of $\mathrm{Cd}, \mathrm{Pb}$ and $\mathrm{Zn}$ in contaminated soils near mine, in: 19th World Congress of Soil Science Symposium 3.5.1: Heavy Metal Contaminated Soils, Brisbane, Australia, 16 August 2010.

[7] G. Dermont, M. Bergeron, G. Mercier, M. Richer-Laflèche, Soil washing for metal removal: A review of physical/chemical technologies and field applications, J. Hazard. Mater. 152 (2008) 1-31.

[8] FRTR, 2.2.1 Data Requirements for Soil, Sediment, Bedrock and Sludge, Retrieved 16 April 2014, from http://www.frtr.gov/matrix2/section2/2_2_1.html, n.d.

[9] L.G. Torres, R.B. Lopez, M. Beltran, Removal of As, Cd, Cu, Ni, Pb, and Zn from a highly contaminated industrial soil using surfactant enhanced soil washing, Phys. Chem. Earth 37-39 (2012) 30-36. 
Y.S. Ng, B. Sen Gupta, M.A. Hashim, Performance Evaluation of Two-Stage Electrokinetic Washing as Soil Remediation Method for Lead Removal using Different Wash Solutions, Electrochimica Acta 147 (2014) 9-18. DOI: doi:10.1016/j.electacta.2014.08.124

[10] M. Isoyama, S.-I. Wada, Remediation of Pb-contaminated soils by washing with hydrochloric acid and subsequent immobilization with calcite and allophanic soil, J. Hazard. Mater. 143 (2007) 636-642.

[11] R. Qiu, Z. Zou, Z. Zhao, W. Zhang, T. Zhang, H. Dong, X. We, Removal of trace and major metals by soil washing with Na2EDTA and oxalate, J. Soil. Sediment. 10 (2010) 45-53.

[12] Z. Yang, S. Zhang, Y. Liao, Q. Li, B. Wu, R. Wu, Remediation of Heavy Metal Contamination in Calcareous Soil by Washing with Reagents: A Column Washing, Procedia Environ. Sci. 16 (2012) 778-785.

[13] D. Voglar, D. Lestan, Pilot-scale washing of Pb, $\mathrm{Zn}$ and Cd contaminated soil using EDTA and process water recycling., Chemosphere 91 (2013) 76-82.

[14] Y.B. Acar, A.N. Alshawabkeh, Principles of electrokinetic remediation, Environ. Sci. Technol. 27 (1993) 2638-2647.

[15] Y.B. Acar, R.J. Gale, A.N. Alshawabkeh, R.E. Marks, S. Puppala, M. Bricka, R. Parker, Electrokinetic remediation: Basics and technology status, J. Hazard. Mater. 40 (1995) 117-137.

[16] S. Shenbagavalli, S. Mahimairaja, Electro kinetic remediation of contaminated habitats, Afr. J. Environ. Sci. Technol. 4 (2010) 930-935.

[17] W.-S. Kim, G.-Y. Park, D.-H. Kim, H.-B. Jung, S.-H. Ko, K. Baek, In situ field scale electrokinetic remediation of multi-metals contaminated paddy soil: Influence of electrode configuration, Electrochim. Acta 86 (2012) 89-95.

[18] N. Boujelben, J. Bouzid, Z. Elouear, Studies of lead retention from aqueous solutions using iron-oxide-coated sorbents, Environ. Technol., 30 (2009) 737-746.

[19] DoE-Malaysia, Contaminated land management and control guidelines No. 1: Malaysian recommended site screening levels for contaminated land, Retrieved 30 January 2012, from http://www.doe.gov.my/portal/wp-content/uploads/Contaminated-Land-Management-and-ControlGuidelines-No-1_Malaysian-Recommended-Site-Screening-Levels-for-Contaminated-Land.pdf, 2009.

[20] M.T. Alcántara, J. Gómez, M. Pazos, M.A. Sanromán, Electrokinetic remediation of lead and phenanthrene polluted soils, Geoderma 173-174 (2012) 128-133.

[21] H.I. Chung, M. Kamon, Ultrasonically enhanced electrokinetic remediation for removal of $\mathrm{Pb}$ and phenanthrene in contaminated soils, Eng. Geol. 77 (2005) 233-242.

[22] W.-S. Kim, S.-O. Kim, K.-W. Kim, Enhanced electrokinetic extraction of heavy metals from soils assisted by ion exchange membranes, J. Hazard. Mater. 118 (2005) 93-102.

[23] B. Murillo-Rivera, I. Gonzalez, M.T. Oropeza-Guzman, V. Escobar-Guerrero, E.G. SumbardaRamos, M.M.M. Teutli-Leon, Evaluation of lead removal from sandy soils using different electrolytes in electrokinetic experiments: prospective for remediation of a real site contaminated with mining wastes, J. Appl. Electrochem. 40 (2010) 1145-1152.

[24] J.Y. Yang, X.E. Yang, Z.L. He, T.Q. Li, J.L. Shentu, P.J. Stoffella, Effects of pH, organic acids, and inorganic ions on lead desorption from soils, Environ. Pollut. 143 (2006) 9-15. 
[25] S. Amrate, D.E. Akretche, C. Innocent, P. Seta, Removal of Pb from a calcareous soil during EDTA-enhanced electrokinetic extraction, Science of the Total Environment, 349 (2005) 56-66.

[26] E.V. Mellis, J.C. Casagrande, M.R. Soares, C. Mara Cristina Pessôa da, O.A.d. Camargo, Sorption of Heavy Metals in Tropical Soils, in: H.M. Selim (Ed.) Competitive Sorption and Transport of Heavy Metals in Soils and Geological Media, Florida, CRC Press, 2012, p. 171-214.

[27] K.-J. Kim, D.-H. Kim, J.-C. Yoo, K. Baek, Electrokinetic extraction of heavy metals from dredged marine sediment, Sep. Purif. Technol. 79 (2011) 164-169.

[28] A. Husain, Pharmaceutical analysis: Theoretical basis of Analysis: Complexometric titrations, Retrieved 29 November 2013, from

http://nsdl.niscair.res.in/bitstream/123456789/771/1/corrected+Theoretical+basis+of+analysis++Complexometric+titrations.pdf, 2007.

[29] R.E. Saichek, K.R. Reddy, Effect of pH control at the anode for the electrokinetic removal of phenanthrene from kaolin soil, Chemosphere 51 (2003) 273-287.

[30] J. Almeira O, C.-S. Peng, A. Abou-Shady, Simultaneous removal of cadmium from kaolin and catholyte during soil electrokinetic remediation, Desalination 300 (2012) 1-11.

[31] W.S. Hummers, R.E. Offeman, Preparation of Graphitic Oxide, J. Am. Chem. Soc. 80 (1958) 1339-1339.

[32] C. Carlon, M. Dalla Valle, A. Marcomini, Regression models to predict water-soil heavy metals partition coefficients in risk assessment studies, Environ. Pollut. 127 (2004) 109-115.

[33] G. Li, S. Guo, S. Li, L. Zhang, S. Wang, Comparison of approaching and fixed anodes for avoiding the 'focusing' effect during electrokinetic remediation of chromium-contaminated soil, Chem. Eng. J. 203 (2012) 231-238.

[34] A.M.N. Silva, X. Kong, M.C. Parkin, R. Cammack, R.C. Hider, Iron(III) citrate speciation in aqueous solution, Dalton Trans. 40 (2009) 8616-8625.

[35] I. Chaari, E. Fakhfakh, S. Chakroun, J. Bouzid, N. Boujelben, M. Feki, F. Rocha, F. Jamoussi, Journal of Hazardous Materials, 156 (2008) 545-551.

[36] Y. Niu, R. Qu, C. Sun, C. Wang, H. Chen, C. Ji, Y. Zhang, X. Shao, F. Bu, Adsorption of Pb(II) from aqueous solution by silica-gel supported hyperbranched polyamidoamine dendrimers, J. Hazard. Mater. 244-245 (2013) 276-286.

[37] Anonymous, Distribution Diagrams of Polyprotic Acids, Retrieved 17 February 2014, from http://www.chem.uoa.gr/applets/AppletAcid/Appl_Distr2.html, n.d 